\title{
ENTENDER LA NATURALEZA PARA CREAR UNA INDUSTRIA. EL PETRÓLEO EN LA EXPLORACIÓN DE JOHN MCLEOD MURPHY EN EL ISTMO DE TEHUANTEPEC, 1865
}

\author{
Francesco Gerali \\ The University of Western Australia, Perth \\ francesco.gerali@uwa.edu.au \\ Paolo Riguzzi \\ Colegio Mexiquense, Toluca \\ priguzzi@cmq.edu.mx
}

Recibido: 18 septiembre 2014; Aceptado: 16 julio 2015.

\begin{abstract}
Cómo citar este artículo/Citation: Gerali, Francesco y Riguzzi, Paolo (2015), "Entender la naturaleza para crear una industria. El petróleo en la exploración de John Mcleod Murphy en el istmo de Tehuantepec, 1865", Asclepio, 67 (2): p102. doi: http://dx.doi. org/10.3989/asclepio.2015.20

RESUMEN: En 1851, John McLeod Murphy fue el oficial inferior de la Armada estadounidense encargado de redactar el informe hidrográfico en la expedición científica en el istmo de Tehuantepec, dirigida por el Mayor Barnard. Durante su exploración, encontró varios criaderos y pozas de petróleo. Años más tarde, en Nueva York, Murphy fue espectador interesado de la explosión de riqueza generada por la extracción del petróleo; el decidió volver a Tehuantepec para explorar más detenidamente las zonas. Los resultados de su visita se plasmaron, en 1865, en un importante estudio de factibilidad acerca de la posibilidad de emprender la explotación petrolífera en la región. Su estudio constituye la primera combinación de exploración geográfica, medición topográfica, interpretación geológica y logística comercial del petróleo mexicano; y representa una fuente hasta aquí no conocida y analizada.
\end{abstract}

PALABRAS CLAVE: Petróleo; Bitumen; Geología; México.

FATHOM THE NATURE TO CREATE AN INDUSTRY: OIL SURVEY DURING THE EXPLORATION OF JOHN MCLEOD MURPHY IN THE ISTHMUS OF TEHUANTEPEC, 1865

ABSTRACT: In 1851, John McLeod Murphy was the junior officer of the U.S. Navy in charge of drafting the hydrographic report during the scientific expedition of the Isthmus of Tehuantepec, directed by Major Barnard. During his survey Murphy observed the oil springs and lakes scattered around the Atlantic Plains of the Isthmus. Years later in New York, Murphy was observing with interest the massive wealth generated by petroleum; he decided to move again to the Isthmus to explore more thoroughly the area. In 1865 Murphy prepared an important feasibility study on the possibility to build oil settlements in South Veracruz. Geographic survey, topographic measurements, geological interpretation, and logistic, are some of the elements proposed by Murphy to describe the making of oil in the uncontaminated and wild Mexican natural landscapes.

KEY WORDS: Oil; Bitumen; Geology; Mexico.

Copyright: () 2015 CSIC. Este es un artículo de acceso abierto distribuido bajo los términos de la licencia Creative Commons Attribution-Non Commercial (by-nc) Spain 3.0. 


\section{INTRODUCCIÓN}

El petróleo en México cuenta con una larga historia, no tan diferente de la de otras naciones productoras. Durante siglos, tantos las civilizaciones autóctonas como el régimen colonial español han utilizado los petróleos -entendidos como bitúmenes líquidos y sólidos - en su estado natural o moldeándolos mediante el calor (Mazadiego Martínez et al., 2011). Una variedad de fuentes atestiguan que, al igual que en otros países, el petróleo fue empleado como pegamento, aislante, combustible, cosmético, medicina. La Corona española importó a Europa chapopote mexicano, pero este comercio era reducido en cantidad y limitado a la península ibérica (Gerali, 2013). Por otra parte, en algunas áreas de Canadá y Estados Unidos al petróleo se le consideraba un peligro para los pozos de agua y de sal; y en México, las grandes chapopoteras causaban la pérdida de mucho ganado, engullido en las pozas de pez (Sánchez, 2009).

La chapopotera se puede considerar el símbolo histórico del petróleo en México; ningún otro país dispone, en su territorio, de una concentración tan elevada de pozas y lagunas - de dimensiones variables - desde decenas a centenares de metros cuadrados de superficie. No obstante la gran disponibilidad de la materia prima, ello no había sido suficiente para estimular el uso, el comercio o el estudio científico del petróleo, en términos superiores a aquellos países donde este último escaseaba. Si bien tuviese ciertas aplicaciones útiles, al petróleo durante mucho tiempo no se le consideró importante, por ser una materia prima de fácil sustitución. En la primera mitad del siglo diecinueve, los minerales considerados cruciales para las modernas actividades productivas eran otros: carbón, hierro, cobre, plomo -y sus aleaciones, fruto di decenios de estudios y experimentaciones llevados a cabo por científicos y tecnólogos - que constituían insumos primarios para la fabricación de maquinarias, ferrocarriles, calderas y armamento (Gerali, 2012a).

La entrada del petróleo al círculo de los minerales de importancia comercial se afianzó a partir de los años sesenta del ochocientos, con la lenta construcción de un sistema de extracción y e refinación de tipo industrial (Frederick, 1866). Justo en ese lapso, de forma paralela a naciones más desarrolladas, en México se hicieron intentos por activar la explotación. Entre 1864 y 1865, en particular, hubo proyectos para dejar atrás la secular recolección manual del chapopote e introducir al sistema de la perforación mecánica para extraer fuertes cantidades del crudo (Gerali y Riguzzi, 2013).
En aquel momento, el nivel global del conocimiento acerca del petróleo se restringía a un número limitado de teorías y nociones empíricas incapaces de explicar sus mecanismos de formación y acumulación. $Y$ en México, la comunidad científica mexicana casi no había prestado atención al estudio del petróleo o al fenómeno de las chapopoteras, si se excluyen algunas observaciones sobre la posible relación con la actividad de los numerosos volcanes diseminados en el territorio (Morelos, 2012).

Planteamos aquí que el punto de partida de la moderna observación geológica y experimentación científica alrededor del petróleo mexicano, con el propósito di explotarlo de forma comercial, tuvo lugar en las planicies atlánticas del Istmo de Tehuantepec a mediados de los años sesenta. En 1865, el ingeniero estadounidense John McLeod Murphy llevó a cabo una exploración extensa y detallada de los recursos petrolíferos del istmo, la primera realizada en Méxi$\mathrm{Co}^{1}$. Su viaje de estudio, de cinco meses, dio vida a una combinación pionera de exploración geográfica, medición topográfica, interpretación geológica y logística comercial del petróleo mexicano, que al mismo tiempo se tradujo en un informe muy detallado, y hasta aquí desconocido, sobre la presencia de hidrocarburos en la región.

En este ensayo se analizan el trasfondo, las razones y los alcances del estudio y exploración de Murphy en México. El objetivo es explicar el significado de esta iniciativa científico-comercial, que no fue igualada, por amplitud y precisión, hasta los inicios industriales de la explotación del petróleo a comienzos del siglo veinte. El trabajo se estructura de la siguiente manera: en las primeras secciones, se lleva a cabo la contextualización relativa al conocimiento sobre el petróleo en el istmo de Tehuantepec, la situación económica y política mexicana a mediados de los años sesenta del ochocientos, y la figura de Murphy. En la segunda parte, se analizan las características, internas y externas, del informe realizado por Murphy; en la tercera parte, se examina el contenido del documento en relación con los descubrimientos del petróleo en la región y se presentan los aspectos más relevantes del análisis geológico. Sigue un epílogo, que evalúa el impacto del informe, y unas notas conclusivas.

\section{PRESENCIA Y CONOCIMIENTO DEL PETROLEO EN EL ISTMO}

El Istmo de Tehuantepec es una región que se encuentra en la zona comprendida por los actuales estados de Oaxaca y Veracruz ${ }^{2}$. Se localiza entre los lí- 
mites del Golfo de México en su extremo norte, y por el Océano Pacífico en su extremo sur. El borde estesureste está delimitado por las cadenas montañosas centroamericanas - Macizo y Sierra de Chiapas, y por la plataforma de Yucatán; a occidente por las cadenas de la Sierra Madre Oriental y la del Sur. El Istmo se localiza en las coordenadas que van de los $15^{\circ} 40^{\prime} \mathrm{N}$ a $18^{\circ} 45^{\prime} \mathrm{N}$ de latitud y de los $93^{\circ} 35^{\prime} \mathrm{W}$ a los $96^{\circ} 30^{\prime} \mathrm{W}$ de longitud; su superficie se estima en casi $48 \mathrm{mil} \mathrm{km}^{2}$ (Torres, 2012). El rasgo más visible de la geografía de la región reside en la corta distancia en línea de aire (alrededor de 215 kilómetros) entre los dos océanos, lo cual hizo pensar a estadounidenses y mexicanos que ofrecía ventajas inigualables para la localización de una ruta interoceánica. A lo largo del siglo XIX, ellos se plasmaron en proyectos, por lo general efímeros, de construcción de caminos, canales, ferrocarriles (Glick, 1953).

La existencia de petróleo en el Istmo era conocida desde hace varios años, pero de forma esencialmente anecdótica y superficial. En 1842 y 1843 la exploración del ingeniero italiano Cayetano Moro, por cuenta de un empresario local a quien el gobierno del presidente Santa Anna había otorgado la concesión para construir un canal navegable interoceánico, hizo mención fuentes de petróleo y aguas sulfurosas (Moro, 1844) ${ }^{3}$. En 1844 la atención de autoridades y observadores se dirigió hacia la localidad de Moloacan, ubicada vente kilómetros al sur de la boca del rio Coatzacoalcos en el Atlántico, donde, después de un pequeño terremoto, de algunos volcanes de barro en la zona comenzaron a salir bitúmenes en ciertas cantidades. Se dio primero la intervención de un médico alemán residente en la zona, quien realizó análisis químicos y calificó el petróleo como producto de calidad suficiente para utilizarlo a fines comerciales, vaticinando al mismo tiempo la posibilidad de un sismo catastrófico. El gobierno mexicano a su vez, encomendó una exploración en la zona al conde Gómez de la Cortina (extraordinaria figura di erudito hispano mexicano) y a un militar, el general Orbegozo. Los dos comisionados desmintieron rotundamente la previsión de terremoto, pero confirmaron la presencia de un "gran yacimientos de asfalto" en la zona; sugiriendo, al mismo tiempo, que se encargara a un experto en química y geología, Manuel Robles, la evaluación más precisa del recurso mineral (Gómez y Orbegozo, 1858). Pero la propuesta no se plasmó en la práctica, y es muy elocuente acerca del interés efectivo por el petróleo que el informe de Gómez y Orbegozo, elaborado en 1844 , se publicó sólo catorce años más tarde en el Boletín de la Sociedad Mexicana de Geografía y Estadística.
A mediados del siglo, tras la guerra con México y la transformación de Estados Unidos en una nación continental, se activó una política de expediciones científicas en América Latina, ejecutadas por la Armada estadounidense, con el objetivo de reconocer rutas de tránsito marítimo y fluvial, y proyectar el liderazgo estadounidense sobre ellas (Harrison, 1955). En este marco, el interés por una ruta interoceánica que conectara los centros del este con la costa oeste, se dirigió hacia varias localizaciones centroamericanas, entre las cuales el Istmo de Tehuantepec. Pero en este caso, fue una empresa la que financió y organizó una expedición científica, en 1850-1851, dirigida por el mayor John G. Barnard, del cuerpo de ingenieros de Estados Unidos. Esta misión, integrada por un equipo de 54 ingenieros, tenía por objeto realizar el reconocimiento de la región del istmo y trazar la ruta de un camino interoceánico (Suárez, 2003). El informe Williams de 1852, que presenta la memoria de la expedición, dio a conocer, de forma muy sintética, que se habían localizado dos manantiales de petróleo en la zona, en las localidades de Ishuatlan y Moloacan. En cuanto a la primera, sólo se informaba que el recurso existía "en cantidad muy considerable» y en condiciones de pureza que volverían lucrativa su explotación. En la segunda localidad, se asentaba la existencia de un manantial grande, "un área de muchos acres", añadiendo curiosamente que no era «necesario hablar de la importancia de esta producción espontánea que, "según dicen es inagotable» (Williams 1852, p. 202, 291). Se trataba esencialmente de información genérica acerca de la existencia del recurso, científicamente poco relevante y no especialmente orientada a difundir o subrayar el valor comercial del hallazgo.

Así, la presencia de petróleo como elemento de la naturaleza del área compresa entre Moloacan, Acayucan y Minatitlán se fue repitiendo en varias recopilaciones y publicaciones. Por ejemplo, el párrafo del informe Williams se reprodujo de forma textual en el complemento mexicano al Diccionario Universal, publicado en $1856^{4}$. Mientras que en un relato de viaje de 1860, que gozó de amplia circulación, como el del abad y científico francés Charles Etienne Brasseur de Bourbourg, sencillamente se anotaba la presencia de petróleo en Moloacan, como rasgo distintivo de la localidad (Brasseur, 1984).

El conocimiento superficial y la limitada transferencia de nociones entre México y los demás países en materia, volvía el petróleo mexicano en un recurso latente e ignorado, del cual era provechoso comprender naturaleza y e composición, para evaluar su posible papel en 
el naciente mercado petrolífero mundial. En este marco, se insertaba el proyecto de Murphy.

\section{EL PETRÓLEO EN EL CONTEXTO MEXICANO DE 1865}

Durante los primeros cuarenta años de vida independiente, ni la comunidad científica, los gobernantes - los empresarios mexicanos habían prestado atención a la cuestión del petróleo. Pese a que se conocieran ciertas aplicaciones útiles, durante mucho tiempo no se le consideró importante, por ser una materia de fácil sustitución (Jiménez, 1840; Mellado, 1856). El primer intento de poner en marcha lineamientos de una política petrolera nacional, regida por una legislación específica, lo emprendió Maximiliano de Habsburgo, quien gobernó a México en la breve etapa conocida como Segundo Imperio (1864-1867), y caracterizada por la guerra civil entre imperiales, apoyados por las tropas de Napoleón III, y republicanos, guiados por Benito Juárez. La minería se consideró una actividad estratégica en la economía del Imperio de Maximiliano, y dentro de política dirigidas a la revitalización del sector, el petróleo fue considerado al mismo nivel de importancia que otros minerales industriales, como el carbón, el hierro o el cobre. El gobierno imperial intentó estimular la inversión privada, y promulgó una legislación que reformaba en algunos puntos las coloniales Ordenanzas de Minería, y asignaba un estatus específico al petróleo (Riguzzi y Gerali, 2015).

Esto acontecía bajo el efecto demonstración del auge petrolífero en Pennsylvania, donde, tras el descubrimiento de Edwin Laurentine Drake en 1859, la producción de los pozos tuvo una expansión extraordinaria en unos cuantos años, que tiene pocos iguales en la historia de la explotación de recursos naturales (Brice, 2009). En respuesta a los incentivos externos e internos, entre el noviembre de 1864 y el diciembre de 1865, en México se registraron sesenta y dos denuncios, con el fin de obtener concesiones para explotar el chapopote en todas sus variantes fluidas y solidas: petróleo, bitumen, alquitrán, betún, y asfalto. La mayoría de los denuncios se ubicaba en la franja costera de los estados de Tamaulipas y Veracruz, reconocida como el lugar histórico del petróleo in México, ya desde la época colonial.

Los interesados en el nuevo sector petrolero, de nacionalidad mexicana, estadounidense, española, francesa, parecen ser inversionistas débiles o especuladores, interesados en la reventa de las concesiones, atraídos por los grandes márgenes de ganancia mencionados por la prensa, al informar sobre el boom petrolífero en la costa este de Estados Unidos. Entre las vanguardias de los interesados en el petróleo en México figuró un personaje peculiar como el neoyorquino John McLeod Murphy, quien, como se ha visto, llevó a cabo una expedición pionera para localizar y estimar el potencial de los recursos petroleros del istmo. Al estado actual de la investigación, no hemos podido definir con precisión los orígenes y el grado de autonomía empresarial de la misión de Murphy. ¿Se trataba de una expedición financiada o comisionada por terceros? ¿O de una iniciativa independiente de Murphy, quién miraba a involucrar posteriormente a inversionistas capaces de soportar los fuertes gastos exigidos por la explotación de los manantiales, que trascendían ciertamente su capacidad económica? Dicho de otras formas, ¿era el neoyorquino un agente de intereses más grandes, o representaba una experiencia de wildcatting estadounidense en México ${ }^{5}$. En su informe, Murphy no ofrece información precisa al respecto, salvo decir que en enero de 1865 «revivió el recuerdo» de los yacimientos petrolíferos localizados en la expedición de Barnard, y que, en consecuencia, "acepté llevar a cabo una visita a México», lo que sugiere que alguien más la promovió y le ofreció dirigirla (Murphy, 1865). En términos lógicos e históricos, el interés por una iniciativa de este tipo podía proceder de los círculos económicos neoyorquinos relacionados con las empresas petroleras o con la ruta interoceánica de Tehuantepec; pero también podía emanar del gobierno imperial de Maximiliano, en su intento por encontrar nuevas fuentes de riqueza. ${ }^{6}$ Pero, prescindiendo de esta cuestión, nos interesa subrayar como, a diferencia de otros actores interesado en el petróleo mexicano en estos años, Murphy no fuera un especulador en busca de ganancias fáciles, sino alguien que puso en juego su reputación como hombre de ciencia, militar condecorado y político, en un proyecto arduo y ciertamente riesgoso.

\section{JOHN M. MURPHY, EL PERSONAJE}

Reconstruir la trayectoria personal y profesional de Murphy (Ver figura 1) es pertinente, no tanto por la información biográfica en sí, cuanto por la posibilidad de evaluar si en su perfil había peculiaridades que contribuyan a explicar la originalidad y la primogenitura de su exploración en el campo petrolero mexicano. Murphy nació en 1827 en Westchester County, Nueva York. Fue cadete en la Academia Naval en Annapolis, y sirvió en la marina de su país como guardia de marina, desde 1841 hasta 1852. En esta calidad, participó primero en la guerra con México, que lo vio operar en Veracruz y en Tabasco (1847); y luego, tomó parte en la expedición en el istmo de 
Tehuantepec, dirigida por el Mayor Barnard, siendo el oficial encargado de redactar el informe hidrográfico. Entrenado en la ingeniería naval, fue autor de connotados manuales técnicos sobre barcos y navegación (Murphy, 1849; Murphy, 1860). Tras dejar el servicio militar, en 1855 fue jefe ingeniero inspector de la Ciudad de Nueva York, y en 1857-1858 trabajó como ingeniero de construcción en el Astillero de Brooklyn. Sucesivamente incursionó en la política, y en 1860-61 fue senador del Estado de Nueva York; una vez estallada la Guerra de Secesión, en junio de 1861 obtuvo el mando, con el grado de coronel, de un Regimiento de Ingenieros, parte de la Brigada de Ingenieros Voluntarios del Ejército del Potomac. Renunció a su rango de coronel en diciembre de 1862 y tomó la comisión de teniente en la Marina de la Unión, hasta julio 1864, cuando volvió a Nueva York para trabajar como ingeniero civil.

En el transcurso de su carrera, Murphy desarrolló una conexión prolongada con el sur de México y en particular con el istmo de Tehuantepec. Como se ha visto, tras el episodio bélico, tomó parte relevante en la expedición Barnard, y unos años después, fue contratado por otra empresa estadounidense interesada en construir un camino en el istmo; en esa función, realizó en 1859 la inspección y el levantamiento topográfico de los terrenos disponibles para transporte y colonización (Brasseur, 1984). A partir de esta experiencia, escribió un ensayo sobre el istmo para el recién creado órgano de la American Geographical Society (Murphy, 1859). Y, en 1865, como se ha visto emprendió la exploración petrolera?

No hay información exacta sobre el surgimiento del interés de Murphy por el petróleo, o las conexiones con empresas o inversionistas especializados. Desde Nueva York, sin embargo, Murphy fue espectador interesado de la explosión de riqueza generada por la extracción del petróleo: para 1864, ese estado era el segundo mayor productor de petróleo en la Unión, tras Pennsylvania. La magnitud del negocio impactó sobremanera la economía del noreste de Estados Unidos, y en octubre de 1864 en la ciudad de Nueva York se fundó la primera bolsa petrolera. Basado en su experiencia mexicana, él probablemente vio la oportunidad de una incursionar en la explotación del petróleo en el istmo de Tehuantepec. Oficial de ejército y marina, ingeniero civil, político, explorador, geógrafo. Este era el perfil de Murphy, un tipo de empresario de cultura científica, técnica y administrativa poco frecuente entre el promedio de los aventureros especuladores del petróleo.
Figura 1. John McLeod Murphy (1827-1871)

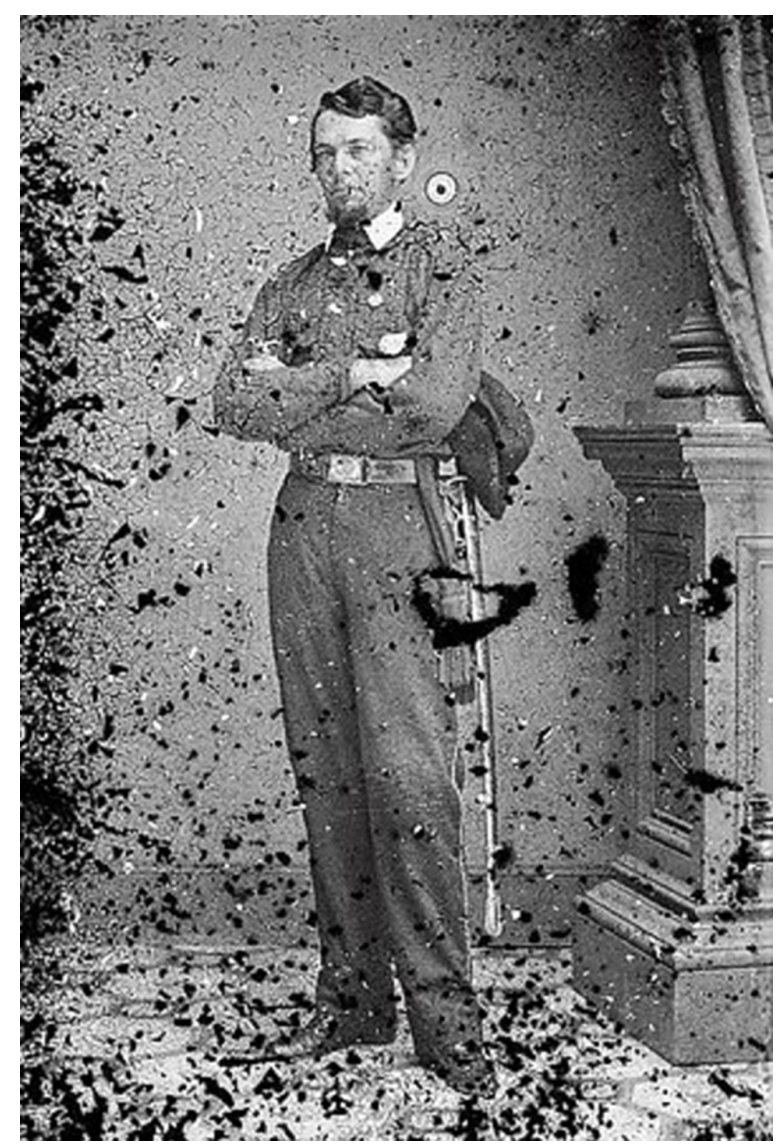

\section{LAS CARACTERÍSTICAS DEL INFORME}

Después de recorrer la región del istmo, en julio de 1865 Murphy volvió a Nueva York con un importante caudal de datos e información que vertió en el informe Petroleum in Mexico, fechado en octubre, y que se publicó como un impreso de 28 páginas, en una edición privada, sin pie de imprenta ni notas editoriales (Murphy, 1865)..$^{8}$ Se trataba de un documento destinado probablemente a la circulación limitada en los círculos empresariales y financieros neoyorquinos, sin recurrir a los canales científicos o la divulgación en medios de más amplia circulación ${ }^{9}$.

En el escrito Petroleum in Mexico, Murphy hizo una descripción de los cinco meses de estancia en el país, basada en el orden cronológico de sus apuntes de campo. Esta fórmula narrativa tiene analogías con el modelo típico de la literatura del viaje científico del siglo XVIII, en el que el autor relata el trayecto que lo ha llevado a un determinado sitio, describiendo geografía y morfología; enfoca su análisis sobre una 'curiosidad' natural en particular (un mineral, un tipo 
de roca y su lugar en la geología local, etc.), presente en aquella área, y luego en sucesión desplaza su mirada hacia nuevos focos de atención, hasta alcanzar la meta final del viaje (Wyse, 2007; Glover, 2010). El texto de Murphy sólo difiere de este modelo -que obviamente no es absoluto- en un elemento. El petróleo era su objetivo único y la gran mayoría de los análisis territoriales que lleva a cabo son propedéuticos a la localización de los bitúmenes en el Istmo y las perspectivas de explotarlos.

En el informe, Murphy localizó con precisión la posición de los depósitos petrolíferos incluidos en los territorios explorados, tanto en las zonas en que obtuvo la concesión como en otras áreas. Bosquejó una verdadera ruta del petróleo en el istmo, de la cual proveyó numerosas coordinadas geográficas, y describió la morfología y la composición geológica de una amplia porción del territorio. No obstante su interpretación de la geología de las zonas exploradas -fincada en un análisis geológico de superficie ejecutado con un limitado número de instrumentos de campo-no siempre sea suficientemente precisa, arroja luz sobre la probable extensión de los depósitos en el subsuelo, incluso en relación con las incursiones volcánicas que han marcado la secuencia estratigráfica del área. En el escrito de Murphy, la interpretación del subsuelo tiene márgenes de incertidumbre, pero se basa en un estudio empírico; ello contrasta con la evaluación -minuciosa aunque en exceso optimista y confiada- de la logística de las vías de comunicación terrestres y fluviales, y de la facilidad de proveerse de varias materias primas necesarias para la realización de los proyectos de extracción y trasporte del petróleo hacia la costa del golfo. Desde este punto de vista, el informe de Murphy tiende a exagerar la dotación de recursos naturales en la región y la posibilidad de aprovecharlos a bajo costo.

En este sentido, utiliza "las aseveraciones de un renombrado estadístico mexicano, el Sr. Iglesias» de 1833, para ejemplificar la gran dotación de recursos naturales y humanos del cantón de Acayucan, en el que se hallaba la mayoría de los descubrimientos de petróleo. Y reproduce una enumeración de aldeas, haciendas y ranchos, animales, plantas, corrientes de agua y materiales, para asentar que no había escasez de recursos en el Istmo, aunque para «todo trabajo de tipo mecánico» había que recurrir a Estados Unidos. Con esta expresión Murphy se refiere a un sistema de perforación estilo pensilvano - una sonda de hierro que percutía el terreno mediante el impulso de un malacate accionado por un motor de vapor. En su visión, la riqueza de los recursos locales y la posibilidad de reclutar mano de obra a bajo costo iba a garantizar el abasto de madera para alimentar las calderas, y construir el derrick, o torre de perforación, así como las fibras para las cuerdas de los pozos. En cuanto a maquinaria y herramienta, es de notar que en aquellos años los Estados Unidos dictaban las normas técnicas y controlaban el mercado; pero ello no ocurría debido a la acción de grandes empresas especializadas, sino por el gran número de pequeñas empresas artesanas, que producían bajo demanda todos los aparatos requeridos por los perforadores ${ }^{10}$ (Beeby-Thompson, 1916).

Las observaciones de Murphy sobre las características físicas de las sustancias bituminosas encontradas representan el primer testimonio de la variedad de los hidrocarbonados - como él mismo los definedel istmo. En su estudio, identificó afloramientos de petróleo, numerosos pequeños lagos de bitumen denso y asfalto, así como depósitos de lignita. Al mismo tiempo, remitió las muestras de muchos de estos minerales a Nueva York, para analizarlas en laboratorio, de manera que ya en el 1865 fue posible estimar las propiedades químicas y las posibilidades de refinar el chapopote del istmo, en función de obtener productos adecuados al mercado de la iluminación y de los lubricantes.

Para sopesar el valor efectivo del estudio de Murphy es preciso recordar la complejidad de la tarea. Se trataba de localizar el petróleo en zonas aisladas, sin vías de comunicación y difíciles de recorrer, sin contar con una cartografía precisa, y que no habían sido objeto de la observación sistemática, sino de forma marginal. En este sentido, el viaje de Murphy representaba un raro y afortunado acoplamiento entre interés económico y exploración científica. El intento, logrado, de localizar terrenos petrolíferos para aplicar un nuevo modelo de investigación y explotación fue un evento significativo en la historia del petróleo en México, aunque sin aplicación.

Murphy propuso una conjetura sobre la medida aproximada de la superficie de las zonas petroleras del istmo:

Desde el principio, me percaté de la semejanza entre los ángulos de rumbo y buzamiento en los estratos geológicos, que se componen -en la sección oriental- de piedra caliza, arena y arcillas. Lo que me llamó poderosamente la atención fue la constancia con la que todos los estratos indicaban la dirección del levantamiento; y desarrollando las 
líneas, hallé que se concentraban cerca del pico del volcán Tuxtla. De hecho, eso no varió en ninguna de la exploraciones sucesivas, lo que me permitió detectar con cierta precisión no sólo el origen sino la zona que encierra todos los depósitos de petróleo en el Istmo. El área en cuestión, tiene un radio promedio de 38 millas y está comprendida entre los meridianos de la Barra de Santa Anna al oriente, y el de San Martín a occidente, en la longitud 93 grados 49' 95" y 95 grados 10' al oeste de Greenwich; mientras que su límite meridional se extiende hasta el paralelo 17 grados 37' de latitud norte. Estos confines abarcan un área de alrededor de 460 millas cuadradas.

Comparando esta aportación con las fuentes técnicas y comerciales de comienzos de siglo XX, cuando México estaba despegando como productor de petróleo, y el istmo se volvió parte integral de esta dinámica, emerge la sorpresiva precisión de di Murphy con respecto a la distribución de los yacimientos en esta área.

En conjunto, y frente a los aciertos mencionados, la principal debilidad del informe residía en los alcances enormes del esfuerzo económico que planteaba, junto con la minimización de los costos y los obstáculos, así como la magnificación de los elementos favorables. El párrafo siguiente, con el cual concluye Petroleum in Mexico muestra con claridad tales elementos.

El petróleo del Istmo, hasta su pleno desarrollo, tendría como mercados primarios a la costa del Golfo mexicano y las West Indies. En la primera zona no habría obstáculos, mientras que en la segunda la proximidad otorgaría una ventaja notable sobre el comercio de Estados Unidos.

Debido a la ausencia de carbón, en México el uso del petróleo se está volviendo generalizado; y en el año pasado las importaciones alcanzaron la cifra de 30,000 barriles de aceite refinado ${ }^{11}$.

La apertura inmediata de la que se puede considerar como una de las regiones petrolíferas mas ricas a nivel mundial, se justifica con los siguientes elementos: la posición geográfica del Istmo de Tehuantepec; la salubridad de su clima; su cercanía a los puertos de Veracruz, Nueva Orleans, y de West Indies; la corta distancia entre los dos oceános, en virtud de la cual se puede manejar el comercio del Pacífico; la abundancia de mano de obra y de materiales; la liberalidad y respeto de las leyes de minería; (...); y las compromisos declarados tanto por el gobierno de los liberales como el del Imperio.
Es probable que Murphy, consciente de que sus recursos financieros no eran en absoluto adecuados para activar el desarrollo, desde cero, del potencial extractivo del istmo, buscara colocar su proyecto con los inversores en Nueva York, con tonos de exaltación promocional. Ello explicaría la sobrestimación del mercado mexicano, el descontar el papel de la competencia del petróleo estadounidense, así como el énfasis con el que había descrito previamente la abundancia de las manifestaciones espontáneas de aceites y bitúmenes o su argumento acerca de la presencia de grandes depósitos subterráneos ${ }^{12}$.

Al mismo tiempo, su confianza en la posibilidad de aprovechar la opción del transporte fluvial para obtener un canal adecuado que conectara a los criaderos con la ciudad de Minatitlán, resultaba excesiva. Al buscar petróleo en el istmo, Murphy entendió la necesidad de romper el cerco que la orografía ponía para el desarrollo de cualquier actividad de explotación, identificando la solución en los ríos y las lagunas, para llevar el petróleo hasta un centro como Minatitlán, desde el cual organizar el comercio del energético. Pero el supuesto de la navegabilidad de los ríos, para embarcaciones del calado necesario para transportar cargamento de petróleo, era ilusorio.

\section{EL VIAJE, LA EXPLORACIÓN Y EL ANÁLISIS DEL PETRÓLEO}

Murphy viajó a México en enero de 1865 y permaneció hasta mayo del mismo año. Llegó acompañado por su socio George S. Drew, un comerciante de Nueva York, con el objetivo de evaluar las posibilidades de iniciar su propio negocio del petróleo en el istmo de Tehuantepec. Al mismo tiempo, reclutó para el viaje a un joven médico cirujano, el Dr. Marcus $A$. Bogie, que fungió de geólogo asistente..$^{13}$ Es de notar que su exploración se valió de la colaboración de expertos mexicanos, en particular de un coronel del cuerpo de ingenieros, así como de otros personajes que acompañaron al grupo en diferentes partes del recorrido. Más en general, Murphy estuvo abierto a la integración de los saberes locales sobre el territorio, mediantes el empleo de guías e informantes, y la realización de entrevistas con propietarios y autoridades locales.

Como hemos visto, Murphy no era un empresario petrolero, pero tenía la ventaja de contar con un conocimiento, de corte científico y profundo, del territorio, por haber participado en misiones geográficas y comerciales. De forma significativa, su informe se abre asentando el nexo con la experiencia previa, el 
reconocimiento topográfico realizado en 1850-1851, durante el cual se habían localizado varios mantos de petróleo:

Pero sin que se le atribuyera valor comercial, más allá de la información acerca de su existencia como fenómenos mineralógicos. Habiendo tenido a mi cargo la parte geológica de aquel importante reconocimiento, estaba yo familiarizado con los lugares en los que se presentaron. En enero próximo pasado se revivió el recuerdo de tales yacimientos petrolíferos, y acepté llevar a cabo una visita a México.

Si en 1850 los criaderos de petróleo del istmo no habían despertado interés comercial, para 1865 el contexto económico del petróleo a nivel mundial planteaba la posibilidad de que tales recursos se convirtieran en riqueza potencialmente aprovechable en gran escala, y no solo para su empleo en los confines nacionales.

Murphy relata la acogida favorable y la protección recibida por las autoridades imperiales cuando entendieron que la búsqueda de petróleo era el motivo de su viaje. Relata que a su llegada a Veracruz, se entrevistó con el Ministro de Fomento, Luis Robles, acerca de los propósitos de su visita. El ministro le proporcionó cartas de recomendación para las autoridades, con instrucciones de facilitar los trámites administrativos en los denuncios de los depósitos de petróleo, por "orden especial del Emperador», interesado en el impacto de los descubrimientos sobre el sector productivo.

Su relato confirma el interés y la protección que el gobierno de Maximiliano otorgaba a los empresarios extranjeros que traían los capitales necesarios para revitalizar el estático sector minero mexicano, y diversificarlo, más allá de la explotación de los metales preciosos. De esta forma, a través del Ministerio de Fomento y de las autoridades locales de Veracruz y Tehuantepec, Murphy sucesivamente no tuvo problemas para efectuar seis denuncios de terrenos petrolíferos, que se publicaron en el periódico oficial «Diario del Imperio», conforme a las Ordenanzas de Minería. Los denuncios, que él y su socio Drew se repartieron de forma igual, se localizaron así: 1. Moloacan. 2. Minatitlán. 3. Coachapa. 4. Cuapinoloya. 5.Sayula. 6. Hacienda de Almagra (véase mapa 1).

Mapa 1. Localización de los denuncios de Murphy y Drew. (Elaboración gráfica Mayelli Hernández)

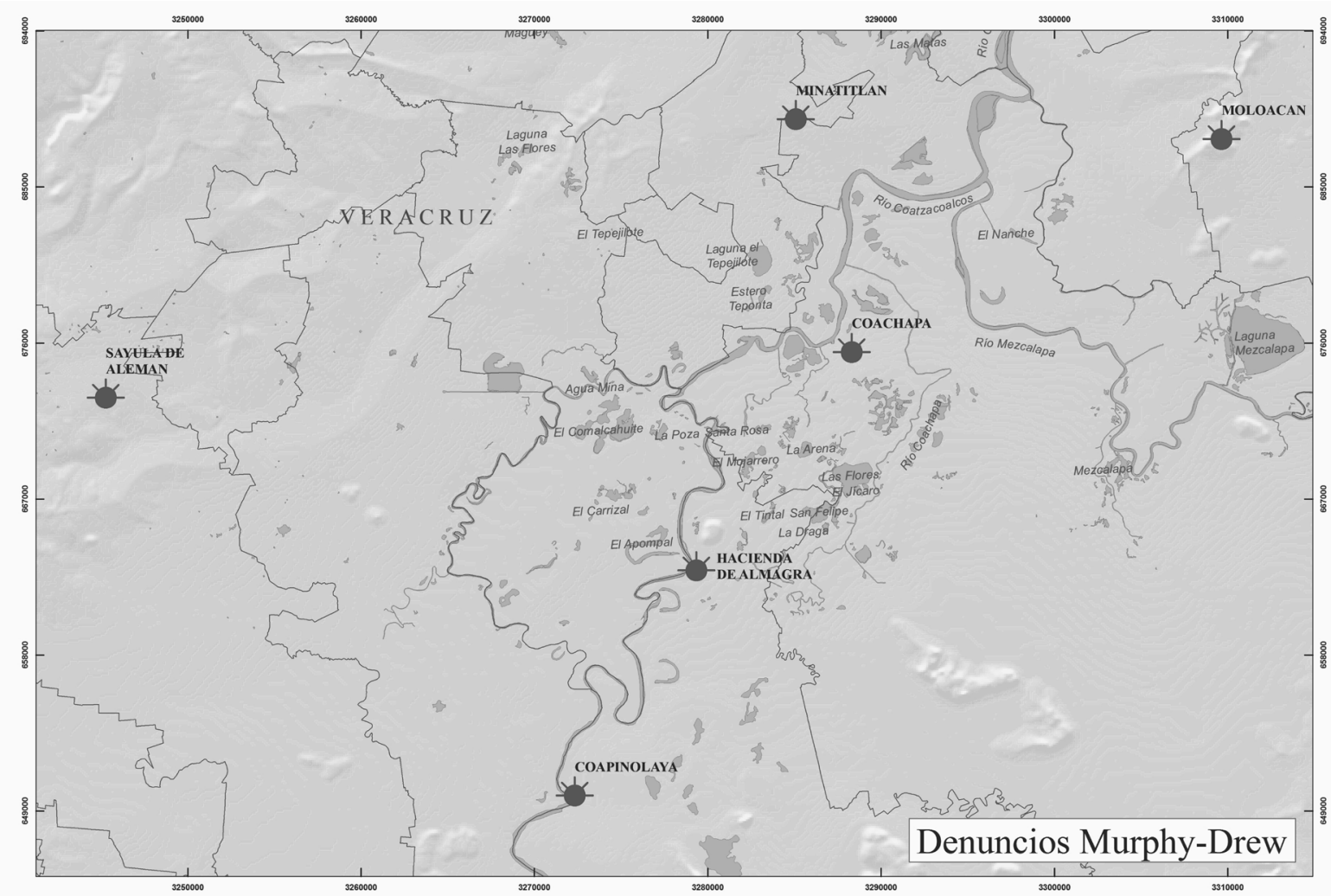


Tras poco más de un mes de su arribo a México, Murphy zarpó del puerto de Veracruz con destino a Minatitlán, la pequeña ciudad que conectaba la extremidad sur del estado de Veracruz con el comercio internacional, gracias a la exportación de caoba y otras maderas. ¿Cuál era su equipamiento técnico? Su texto nos informa que el traslado se emprendió «una vez conseguidos los materiales químicos y las retortas necesarias». El geólogo austriaco Ami Boué en el primer volumen de su influyente obra Guía del geólogo, de 1835, hablando de la dotación necesaria para hacer un trabajo de campo formuló el precepto que los instrumentos del geólogo debían variar en función de la finalidad y la duración de los viajes, y después de la visita al país; y agregó que «en todos los casos, deben reducirse a lo estrictamente necesario, porque si he hecho una y otra vez la misma experiencia, la que si estás lleno de muchas cosas, estás cargando algo sin ninguna utilidad real» (Boué, 1835).

Lo que él definía como estrictamente necesario abarca martillos, picos, cinceles, lima, objetos punzantes, antorchas y cerillos, los mapas geográficos, la brújula, lupas, goniómetro, reactivos químicos, termómetro, inclinómetro, y no mucho más. De hecho, Murphy se equipó con frágiles retortas y alambiques, muy probablemente de cristal o vidrio, que constituyen instrumentos de laboratorio más que de trabajo de campo (Gerali, 2012b). Parece evidente, como confirma el mismo informe, que Murphy llegó al istmo con la intención de llevar a cabo análisis preliminares del petróleo, ya durante su exploración. De todas formas, también remitió a Nueva York una amplia selección de muestras de petróleo por analizar.

Si bien Murphy explica al lector las seis áreas a explorar, no se plantea una meta final a alcanzar en un determinado plazo; se mueve en el territorio sin seguir, en apariencia, un plan establecido, empeñado en una exploración para identificar las fuentes de petróleo y los lagos de bitumen. Por una parte, se apoya tanto en la cartografía existente, decidiendo al mismo tiempo generar sus propios mapas, gracias a la colaboración de sus ayudantes ${ }^{14}$. Por la otra, recoge testimonios locales, modificando su recorrido en función de la información obtenida, descubriendo así nuevas manifestaciones de superficie que lo convencen aún más del gran potencial del istmo para el aprovechamiento del petróleo.

\subsection{Coachapa: los mayores yacimientos del istmo}

La primera localidad que Murphy visitó fue Coachapa, y el punto focal de la exploración fue la Laguna de Alquitrán, de la cual escribió lo siguiente:

Emprendimos el viaje a las Salinas de San Cristóbal, en el Rio Coachapa. Recorrimos una distancia de cinco leguas corriente arriba hasta llegar al Paso de San Cristóbal. En el radio de una milla al oeste existen vastas salinas y fuentes de sulfuro, que contienen abundantes cantidades de petróleo y otros bitúmenes, llevados en superficie de manera constante. (...) El dueño de las salinas, me informó que la presencia de tales productos hidrocarbonatos ${ }^{15}$ constituye un problema, que obliga los operarios a removerlos de los pozos ${ }^{16}$. Al día siguiente nuestro grupo, (...) se trasladó a la Laguna de Alquitrán, en la que se concentran los mayores yacimientos del istmo, como las exploraciones sucesivas demostraron. (...) Abriéndonos camino a través del bosque denso por 2,500 pies, dimos la vuelta a la base de un elevado cerro de piedra caliza gris, repleto de grutas, y llegamos a la orilla del lago, en los llanos de Ojapa. Este lago surge sobre un suelo aluvional denso y negro, cerca del declive del cerro, en el que se hallan calcite, carbonato de lima, fluorita, estalactitas, etc. Está rodeado de vegetación alta, y mide más de un acro. A semejanza del lago de Trinidad, el círculo más externo es una superficie suficientemente compacta como para caminar sobre ella; pero el centro es suave $y$, bajo los rayos verticales del sol, brilla como pulido azabache. En varios puntos, hay estanques pequeños de agua de colores iridescentes, y en otros el bitumen fluido burbujea, como en estado de ebullición permanente. En ocasiones, las burbujas se agregan para formar pequeños conos altos dos o tres pies, con vapores, explosiones y desbordamientos. Los yacimientos de petróleo del Istmo son conectados por debajo de la superficie, y como prueba se puede citar que cada vez que en la Laguna de Alquitrán se verifica una fuerte ebullición o una explosión espontánea, ésta se repite en todos los demás, aunque estén a cierta distancia los unos de los otros ${ }^{17}$. Los olores que se desprenden de los lagos son iguales a los de los pozos petrolíferos y depositos bituminosos de Michigan y Canadá. (...). Desde estos varios puntos de vista, los depósitos del Istmo tienen semejanza con los grandes lagos petrolíferos cerca de Santa Barbara, en California. 
Mapa 2. Particular del rio Coachapa: las salinas de San Cristóbal y la áreas petroleras alrededor (Shufeldt, 1872)

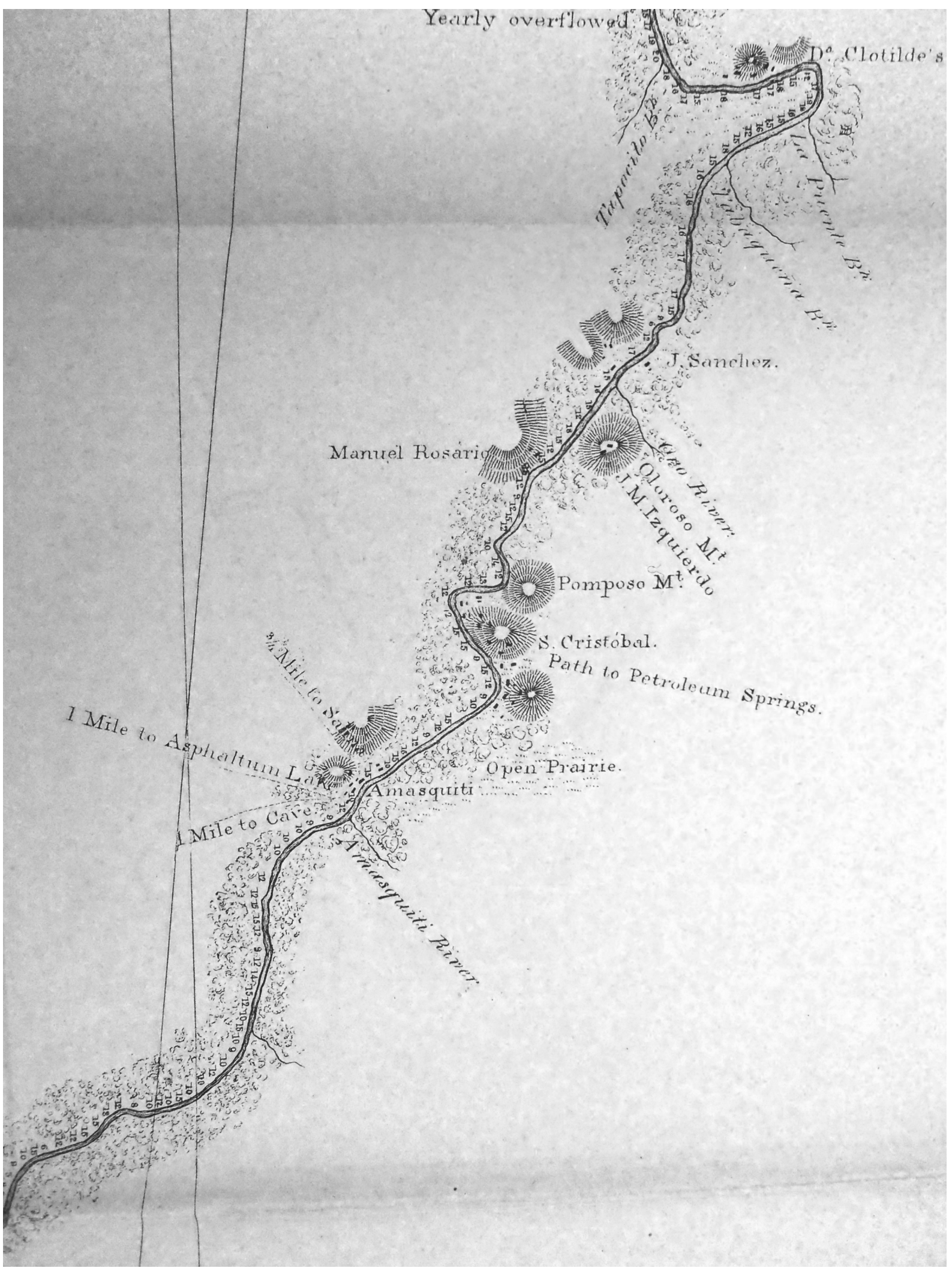


En la zona de Coachapa (véase mapa 2), Murphy halló elementos de superficie generalmente asociados con los depósitos de petróleo, como el gas de sulfuro de hidrógeno y agua sulfurosa. El ejemplo del lago de Trinidad no es casual; el gran 'Pitch Lake', lago de Alquitrán de la Isla de Trinidad, era el que mejor describía el concepto de lago de gran tamaño, formado por el constante desbordamiento de petróleo, en la misma porción de terreno, en el trascurso de periodos largos y por consiguiente oxidado y solidificado per la acción del oxígeno (Forbes, 1958). A continuación, comparó sus observaciones con las muestras de otros lagos norteamericanos, con notables alcances descriptivos. Mediante tales ejemplos Murphy ofrece una explicación de lo que es realmente una enorme chapopotera, tanto al lector familiarizado con la literatura científica, como al lector desprovisto de conocimientos específicos. La chapopotera, como hemos mencionado, era la expresión física predominante en México de la probable presencia de petróleo en el subsuelo adyacente ${ }^{18}$. Explicar este fenómeno físico era la clave para dar a entender a los potenciales inversionistas estadounidenses de qué forma se presentaba el petróleo en la nación vecina.

En este punto del informe, el autor combina la observación naturalística con el análisis de laboratorio, para delucidar de qué forma el petróleo de esta area podía colocarse en el mercado de la refinación. Al respecto, dio cuenta de los resultados obtenidos en los exámenes conducidos por el profesor S.R. Percy, del Médical College de Nueva York, sobre las muestras trajidas de la laguna de alquitrán en Coachapa:

Mediante el calentamiento cuidadoso esta sustancia se vuelve ligera, y puede trasvasarse de un recipiente a otro. Contiene en su interior cierta cantidad de agua, que inicialmente dificulta la distilación (...). En un examen se calentó una porción de aceite mineral en envases abiertos, hasta la eliminación de toda el agua; luego se tapó el envase y se procedió a la distilación. Bajo este tratamiento, una masa de 25 libras de peso rindió un galón de aceite, así que una tonelada produciría 89,6 galones. En una manipulación posterior se empleó un mejor método, y 25 libras de masa rindieron 9,5 pintas de aceite. Mediante la distilación fraccionada, a 400 grados Farenheit, 100 parte de éste generaron: 17 partes de aceite de iluminación y 83 partes de aceite lubricante.

Tales resultados distaron de ser alentadores. El petróleo recolectado presentaba dificultades para refinarse a raíz del nivel elevado de agua que contenía; además, en cuanto a rendimiento final, la proporción entre crudo y refinado era sustancialmente baja. Simplificando las palabras de Murphy y trasformando todos los valores en decimales, es posible establecer que $11.4 \mathrm{~kg}$ de producto drenado de agua, producirían $5.4 \mathrm{~kg}$ di sustancia oleosa al llevarse al punto di ebullición. Esta última cantidad, tras un proceso de destilación fraccionada ${ }^{19}$, que culmina en 212 grados Celsius, producían sólo 920 gramos de aceite iluminante; el residuo se clasificó como aceite lubricante, de hecho un aceite pesado, de bajo valor comercial. Murphy, para matizar esta información desfavorable, intentó relativizar el resultado, afirmando que las muestras procedían de la superficie, pero que la laguna podía ofrecer mucho aceite mineral, «una fuente inagotable», de calidad superior a la de la muestra recolectada (Murphy, 1865).

\subsection{Almagres y Cuapinoloya: los campos de fuego}

A una distancia de 2 millas del área de las salinas de San Cristobal, en dirección Norte-Oeste, Murphy cruzó una cadena de colinas calcáreas (Cerros de las Salinas), que se extiende por las praderas hasta la ribera oriental del Coatzacoalcos, y forma parte de los límites septentrionales del Potrero de Ojapa. En uno de los esperones de la cadena, situó a la villa de Almagres, mientras que en el otro ubicó el Cerro de Cuapinoloya.

En el margen oriental del declive están los depósitos de sal, sulfuro y petróleo (...), que agitan el lago de forma constante. Las «agitaciones» son especialmente intensas durante la temporada de los Nortes, y cuando los volcanes de Orizaba y Tuxtla emiten gases. Aproximadamente una vez al año la laguna de Alquitrán es objeto de combustión espontánea y la superficie entera se recubre con lenguas de fuego, acompañadas por masas de humo denso, que impregna el aire con fuerte olores bituminosos. Una de estas combustiones tuvo lugar el día de nuestra visita (...), poco después de que nos retiramos, y se prolongó hasta después del ocaso. Las flamas generaron un calor muy grande, y nubes de humo negro obscurecieron el cielo sobre el lago, ofreciendo un espectaculo que recuerda la descripción de los "campos de fuego» del Caspio.

Entre las tradiciones aztecas está la de venerar los fuegos generados por medios no visibles; y en los escritos de Heródoto, Elia, Strabo y Plutarco hay referencias a los incendios de Apolonia (Libia), Zakunthus y Ecbatana (Irán), que eran objeto de adoración supersticiosa en Oriente. En cuanto a los fuegos en los lagos del Istmo, todas las localidades contiguas exhi- 
ben las huellas de de civilizaciones grandes y desarrolladas. (...) Transcurrimos varias horas alrededor de la laguna, explorando, reconociendo y recolectando muestras(...) De regreso a San Cristobal, me enteré que en el radio de legua y media desde la ribera del Coachapa, rumbo al sureste, existen otros seis lagos más pequeños, concentrados en un espacio de 300 acres. Se les describe como muy parecidos al de Alquitrán, y sin duda se alimentan de las mismas corrientes.

La descripción puntual de la segunda etapa de la exploración se enriquece con el apunte histórico sobre la relación entre las poblaciones prehispánicas y la presencia del petróleo. ${ }^{20}$ Más relevante es el argumento, que Murphy reiteró en diferentes partes del informe, de la relación estrecha entre la actividad volcánica y el burbujeo de los lagos bituminosos; además, sostuvo la hipótesis del origen inorgánico - volcánico del petróleo mexicano, alineándose en esto con las obra y las teorías proporcionada medio siglo antes por Alexander Von Humboldt y el mexicano Andrés Manuel del Río. Pero, salvo algunas referencias con escaso valor probatorio, no profundizó en las razones de su convencimiento. Al finalizar esta sección, en la que se combinan observación científica y nociones históricas, Murphy se conectaba nuevamente con su objetivo primario: la exploración del área que en su denuncio llama de forma genérica Cuapinoloya, para comprobar la existencia de otros depósitos superficiales.

\subsection{Moloacan, entre lignito y petróleo}

Sucesivamente, Murphy y su equipo decidieron examinar el territorio al oriente de Moloacan, y se trasladaron a Ishuatlán, un eslabón más en la larga cadena de depósitos petrolíferos, que en texto presenta en estos términos:

Se trata de una capa de lignito y otras sustancias arcillosas, esquistos bituminosos, etc., entremezclados con materia orgánica, y situada al fondo de un barranco profundo a espaldas del Campo Santo. La lignito tiene una estratificación horizontal, que remite a una era reciente de formación. Su color es negro café, con cierta textura de residuos de madera, y al quemar desprende un olor empireumático. Una cresta de marga yesífera y piedra arenisca gris recubre los estratos, y forma muchas torceduras. Los componentes bituminosos de los enquistos sin duda se originan del petróleo ${ }^{21}$, y es probable que haya por debajo un manto de carbón obscuro. El informe del Profesor Percy asienta que: este lignito es de color marrón obscuro, está compuesto por capas horizontales fácilmente separables, revestidas en varios puntos con sequióxido de hierro. Calentada en horno de crisol, 100 partes proporcionan: materia combustible volátil, 39.04 partes; Coke, 60.96 partes. Mientras que, al distilarse en alambiques cerrados, arroja: Aceite parafinado, 14.04 partes; Agua amoniacal, 25 partes; Coke, 60.96 partes

Alrededor de quince años antes, en la Escocia central, el químico James Young, empezó una lucrativa actividad de refinación y comercio de aceite y gas para la iluminación mediante la distilación de bitúmenes que se desprendían del 'channel coal' de la mina de carbón de propriedad de su familia. Este negocio se aunaba a la venta de coke, parafina mineral, y agua amoniacal -las dos últimas eran útiles en varios sectores industriales y civiles. Justo cuando Murphy se hallaba en México, en Pennsylvania iba despegando el mercado de la parafina mineral derivada del petróleo- hasta entonces considerada como una impureza que obstaculizaba la extracción del crudo (Butt, 1983).

El análisis de Percy arrojaba resultados positivos en este renglón: la destilación ofrecía un rendimiento de cien por ciento de producto potencialmente comerciable. Curiosamente, en el informe no hay comentario de satisfacción por este hallazgo, aunque en más de un punto se muestra interés por la posibilidad de emprender negocios paralelos.

\subsection{Sayula y Acayucan: petróleo a baja profundidad}

Una vez concluidos los preparativos para un nuevo recorrido, Murphy viajó hacia Sayula, una localidad de alrededor de 1,500 habitantes, a tres millas de Acayucan, omitida en el mapa del Mayor Barnard. ${ }^{22}$ En el camino recorrió las localidades de Cosoliacaque, Jaltipan, Soconusco y Acayucan.

Todas (...) se sitúan sobre lomas de arenas gruesas blancas, tiza y yeso, a cuyos pies transcurren numerosos pequeños caudales que contienen chapopote, turba y otras materias vegetales impregnadas con bitumen. Con base en los indicadores de superficie que abundan en el distrito, no es arriesgado considerar que los pozos abiertos en casi cualquier punto del área en cuestión, arrojarán petróleo a una profundidad inferior a los 250 pies.

Murphy conjetura acerca de la existencia de un depósito petrolífero a una profundidad inferior a los 75 metros, pero sin proveer pruebas de ningún tipo. En realidad, no es posible establecer la profundidad de una capa potencialmente productiva mediante 
una simple evaluación de la superficie; particularmente en un área de la cual se conocía solo marginalmente la topografía, y de la que se ignoraba casi por completo la geología.

Por lo que se refiere a Sayula, el informe ofrece la siguiente información:

Aquí, las fuentes de petróleo derivan en un barranco no tan profundo, a partir del lecho de un pequeño arroyo que cruza con rumbo N.N.W. y S.S.E. (...) di instrucciones al Coronel Castro, para que elaborara un mapa, y al Dr. Bogie para recolectar muestras, al mismo tiempo que yo me dedicaba a reconocer las características geológicas (...). Por lo que se refiere propiamente al petróleo, el Dr. Bogie, que lo ha analizado en la medida de lo posible desde allá, asevera que es superior a cualquier otro en el Istmo, y se asemeja al aceite de los pozos de Guadalupe (...). El análisis de las muestras recolectadas, de acuerdo al reporte del Profesor Percy, es el siguiente: «la masa aceitosa semi fluida, una vez separada el agua, contenía $87 \%$ de aceite pesado. La distilación fraccionada de tal aceite a 400 grados $F$, produjo $21 \%$ de aceite de iluminación.

Mapeo, observación geológica, recolección de muestras, análisis preliminares: el pequeño equipo de Murphy no tenía quizás experiencia en materia de petróleo, pero era muy apto para el trabajo de campo. Al cabo de pocas semanas, sus integrantes identificaron petróleo, bitúmenes y lignito, midiendo coordenadas, distancias y topografía del área y fijándolas en papel. Durante la redacción de su informe, entre julio y octubre, Murphy siguió recibiendo información de sus asistentes; en particular de que el petróleo de Acayucan era de calidad parecida a la de la nafta ligera que fluía, de manera episódica, de una roca atrás del célebre santuario de la Virgen de Guadalupe, en las afueras de la Ciudad de México. Sin embargo, el resultado de Percy, más preciso y confiable, mostró que si bien aquél petróleo rendía más del doble de masa drenada que el denso bitumen de las salinas, la cantidad de aceite de iluminación permanecía poco satisfactoria.

\subsection{Epílogo}

A lo largo de cinco meses en México, Murphy estrechó relaciones políticas, aseguró casi por completo las concesiones de explotación relativas a sus descubrimientos, y llevó a cabo la exploración petrolífera más importante en el México del siglo XIX. ${ }^{23}$ Dejó la región, a finales de mayo, para volver a Nueva York, dejando en el sitio al Dr. Bogie, y enviando sucesivamente a un ingeniero, para continuar la recolección de muestras (Murphy, 1865). Su socio Drew y él consiguieron solo cinco de las seis zonas denunciadas y descritas en el informe, sin lograr los derechos de explotación sobre Moloacan.

Mucho más importante, es que, de todas formas, ninguna de las concesiones dio origen a trabajos de perforación o intentos de explotación. Pese a que algunos diarios mexicanos, en mayo de 1866 , reportaron que había empezado la explotación de una mina de petróleo en el istmo de Tehuantepec, "de abundancia maravillosa», eso parece responder esencialmente a una operación publicitaria, orquestada por el mismo Murphy, que en ese momento había vuelto a México, probablemente para defender las concesiones. ${ }^{24}$

Podemos inferir que, en vista del volumen muy grande de la inversión y los riesgos asociados, Murphy no consiguió convencer a los financiadores potenciales; y que las circunstancias mexicanas, con la intensificación del conflicto militar, que concluyó con la caída de Maximiliano y el triunfo del bando republicano en 1867, desdibujaron las perspectivas del negocio petrolero. De hecho, la legislación del subsuelo, así como todas las concesiones petroleras asignadas por el gobierno imperial, fueron canceladas al restaurarse la república (Riguzzi y Gerali, 2015).

Por su parte, Murphy pareció abandonar el proyecto o perder interés en él, lo que podría avalar la posibilidad de que su misión en el istmo, más que una iniciativa individual, fuera por encargo de un grupo de inversionistas. Ante el hecho de que el informe no fue suficiente a convencerlos de las perspectivas del negocio, a Murphy no quedaba más opciones que el repliegue. Desde este ángulo, el hecho que el texto fuera un documento impreso, plantea la interrogante de por qué no circuló sucesivamente, por lo menos de forma parcial, ni recibió publicidad indirecta o mención en la prensa. La única referencia del informe de Murphy, la ofreció, veinte años después, un documento elaborado por un funcionario del Department of Interior de Estados Unidos, sobre la producción, tecnología y usos del petróleo, que reprodujo una docena de líneas del informe de Murphy, para avalar la existencia de abundantes fuentes en México (Peckham, 1885).

La respuesta más plausible era que se tratara de un texto comisionado y por lo tanto vinculado por el derecho de propiedad. Todavía en el agosto de 1867 el New York Times publicó un artículo sobre el petróleo en México, que evidencia con claridad la inspiración 
- la autoría de Murphy, por la presencia de algunas frases muy similares a las del informe, y por recordar (sin citar la existencia del informe) que la gran riqueza petrolera del istmo de Tehuantepec había sido cuidadosamente explorada, y adquirida en concesión, por él (New York Times, 11 de agosto de 1867). Pero esta fue la última aparición pública del tema, y Murphy, pese a su regreso a México durante dos años como cónsul en Tabasco, dirigió su atención hacia otras cuestiones, como el estudio de las características de las fibras de ixtle (Department of Agriculture, 1869). En 1869, obtuvo una patente de invención para un dispositivo de abertura y cierre de las latas de aceite mineral; y es de notar que aún en 1870, poco antes de fallecer, convencido de la existencia de petróleo en el istmo, Murphy volvió a efectuar el denuncio de varios criaderos de petróleo en Minatitlán, a través de representantes (Scientific American, 6 de noviembre de 1869; Riguzzi y Gerali, 2015).

\section{NOTAS CONCLUSIVAS}

Murphy era un individuo emprendedor y de gran cultura científica, perteneciente a la elite política neoyorquina, y que conocía muy bien el potencial económico del petróleo. Su conciencia de la necesidad de estudiar la naturaleza del territorio y aprehender sus características para evaluar la riqueza del subsuelo, le permitió realizar una exploración científica. Esto era todavía un sistema aún poco utilizado para buscar el petróleo, lo cual acerca su experiencia mexicana al nivel de otros países en donde la asociación entre ciencia e inversión empresarial había sido provechosa

\section{NOTAS}

1 La primera exploración en gran escala para localizar otros minerales industriales en México, con el empleo de geólogos, fue la de la empresa estadounidense Mexican Coal and Iron, en 1856, con el apoyo del gobierno mexicano (Pletcher, 1952).

2 Pequeñas porciones de esta región geográfica corresponden a los estados de Chiapas y Tabasco

3 El ingeniero Gaetano Moro, un exilado liberal italiano, tuvo el encargo de dirigir la exploración y el levantamiento topográfico del istmo de Tehuantepec, en 1842 y 1843. A la misión tomaron parte el astrónomo Manuel Robles, y varios oficiales.

4 Apéndice al Diccionario universal de historia y geografía. Colección de artículos relativos a la República Mexicana, para la explotación de los hidrocarburos, tales como Estados Unidos, Rumania e Italia. El problema principal, como hemos mencionado, es que su estudio permaneció sustancialmente desconocido. Parece incuestionable que la difusión del informe hubiera generado un nuevo acervo de conocimiento geológico, geográfico y logístico. Sin embargo, la oportunidad de incrementar los saberes aplicados al subsuelo mexicano permaneció inerte.

En la primera década del novecientos, la construcción definitiva del ferrocarril interoceánico de Tehuantepec, llevó al re-descubrimiento de varios pozos productivos, justo en algunas de las zonas identificadas por Murphy. Y alrededor de Minatitlán se fue montando un complejo integrado extracción-refinación-transporte, con la construcción de una de las refinerías más importantes de México y un oleoducto (Garner, 2013).

Obviamente no es posible demostrar que la difusión del informe de Murphy hubiera significado acelerar el surgimiento de la industria petrolífera en el istmo. El atraso industrial de México, los bajos niveles de consumo de petróleo, satisfechos a través de la importación de crudo estadounidense, la ausencia de una política específica (la primera legislación sobre petróleo es de 1901), fueron factores que en la segunda mitad del siglo XIX inhibieron el desarrollo del sector petrolífero en la república mexicana. Queda sin embargo claro que John Mcleod Murphy, el mayor experto en la geología del Istmo en su tiempo, había interpretado con cuarenta años de adelanto varios puntos clave para la localización y explotación del petróleo de Tehuantepec.

México, 1856. El geógrafo Manuel Orozco y Berra tuvo a su cargo esta recopilación.

5 El término wildcatter se refiere a buscadores de petróleos independientes, y que por lo general operaban con altos niveles de riesgo económico, fuera de las zonas petrolíferas más conocidas.

6 De hecho, en 1865-1866, Maximiliano financió el reconocimiento geológico de las cuencas carboníferas del estado norteño de Coahuila, por parte del ingeniero austro-estadounidense Jacob Kuchler (Anderson, 1959)

7 La conexión con México se prolongó en 1867, cuando Murphy fue nombrado cónsul de Estados Unidos en Tabasco, cargo que mantuvo hasta mediados de 1869. Falleció en Nueva York en 1871. 
8 La consulta del database bibliográfico internacional 'WorldCat' indica que el único ejemplar catalogado y conocido del texto Petroleum in Mexico está en la New York Public Library. Agradecemos aquí la colaboración del Profesor Houston Mount de la Central East University of Oklahoma y de la Dra. Andrea Boardman del Clemence Center for the History of the SouthWest en la Southern Methodist University, para localizarlo. El Dr. Kerry V. Magruder y la Dra. JoAnne Palmeri, de la History of Science Collection de la University of Oklahoma, nos facilitaron la consulta del texto a través de un préstamo interbibliotecario.

9 Todas las citas del informe de Murphy han sido traducidas al español por los autores, que están preparando una edición integral comentada de este texto. Salvo indicación explicita, todas las citas en cursivas proceden de Murphy, 1865.

10 Aún en la década de 1870, buena parte de las herramientas se fabricaban en el lugar de extracción, por parte de los mismos trabajadores de los pozos; al mismo tiempo, en Nueva York y Pensilvania iban surgiendo las primeras empresas que producían en serie materiales específicos para la industria petrolífera.

11 Aquí el texto incurre en una sobrestimación, de amplísimas proporciones, del mercado mexicano, que en 1864 había importado poco más de una décima parte del volumen señalado por Murphy.

12 En el mismo sentido, la referencia a la "salubridad del clima" constituía una aseveración muy distorsionada, ante las condiciones extremas de la región y la recurrencia de epidemias.

13 La presencia del Dr. Bogie en el equipo no respondía sólo a sus conocimientos químicos, sino a la necesidad de contar con un médico durante la exploración en el istmo.

14 No hemos podido localizar este corpus cartográfico manuscrito.

15 Murphy usa la palabra hidrocarbonados en lugar de la palabra hidrocarburos. La primera era muy utilizada en tratados de farmacéutica y química orgánica desde la primera mitad del siglo XIX, para referirse a substancias oleosas de varias naturaleza, compuestas por la mayor parte de carbono e hidrogeno. La segunda se encuentra con más frecuencia desde la segunda mitad del mismo siglo, referida especialmente en la definición de las substancias gaseosas y oleosas que pertenecen a la familia de los bitúmenes.

16 La acumulación de sal derivada de la extinción de los antiguos océanos puede localizarse en las inmediaciones de los depósitos de materia orgánica de la cual se genera el petróleo. Este, migrando a través de las fisuras de las rocas, contaminaría la sal. Ya a mediados del ochocientos la recolección del petróleo, depurado de la sal, había originado una rudimentaria refinación del petróleo en combustible para lámparas y tónico vigorizante en Pittsburg, Virginia.
17 Murphy de hecho no tiene ninguna más prueba que ésta para confirmar la idea de un solo y gran yacimiento subterráneo capaz de alimentar todas la fuentes de petróleo del área.

18 La tesis de la correspondencia vertical entre manifestaciones superficiales de hidrocarburos - depósitos subterráneos era muy común en la época, pero engañosa. El conocimiento limitado de los mecanismos de migración del petróleo hacia la superficie no había aún llevado a entender que el petróleo podía emerger, siguiendo una ruta diagonal larga y tortuosa, muy distante del depósito de origen.

19 La temperatura de ebullición de la masa oleosa se hace subir lentamente y se estabiliza en ciertos grados de manera que se puedan obtener destilados cada vez más volátiles.

20 Murphy registró la presencia de abundantes restos de esculturas antiguas, en particular a lo largo de las cuencas hidrográficas y en proximidad de los mantos petrolíferos de Ishuatlan, Acalapa, Capoacan, Monte Encantado y Sayula; eso lo llevó a concluir que "no es improbable, entonces, que antes de la conquista los pueblos indios conocieran tales fuentes con sus misteriosos fuegos, y que, al igual de sus símiles en India, Persia y Grecia fueran altares de adoración religiosa pagana." En este caso, los argumentos de Murphy acerca del culto del petróleo, tienen una debilidad: a diferencia que en Grecia, Sicilia, Medio Oriente, en México los hallazgos de la arqueología no confirman la existencia de una veneración, más allá de evidencias sobre la variedad del empleo de la sustancia (Cyphers, Hirth y Grove, 2008).

21 Murphy estaba evaluando de forma errónea el origen del bitumen que acompaña el lignito, en perjuicio de la interpretación del potencial petrolífero de esta porción de terreno. Los lignitos se clasifican como un grupo de carbones fósiles en un estadio de carbonización relativamente poco avanzado.

22 La cartografía resultado de la exploración de 1850-1851, del mayor Barnard, representó un punto di referencia para el conocimiento geográfico del istmo durante dos décadas. A partir de 1872, se elaboraron mapas precisos, dibujados con los datos recogidos en la exploración del istmo dirigida por el capitán Robert W. Shufeldt.

23 La lista de las concesiones otorgadas por el gobierno de Maximiliano se publicó en Ministerio de Fomento, 1866. En el informe, Murphy afirma que el interés despertado en la zona del istmo por su exploración había resultado en denuncios presentados por otro estadounidense en un área cercana a Acayucan, citando el caso del mismo cónsul estadounidense en Minatitlán, Hoyt.

24 La Sociedad, 27 de mayo de 1866, p. 2; La Sociedad, 18 de mayo de 1866 . Murphy y socios supuestamente podían gozar de la posesión de los criaderos hasta marzo de 1866. Después de esta fecha, si el trabajo de explotación no arrancaba, la concesión se anularía; de aquí, la necesidad de mostrar que había alguna actividad en curso. 


\section{BIBLIOGRAFÍA}

Anderson, W. M. (1959), An American in Maximilian's Mexico, 1865-1866: The Diaries of William Marshall Anderson. San Marino, Ca, Huntington Library

Beeby Thompson, A. (1916), Oil-field exploration and development; a practical guide for oilfield prospectors and operators, with which is incorporated a discussion of the origin and distribution of petroleum, and notes on oil-field legislation and customs. New York, Van Nostrand.

Boué, A. Y.; Leonhard, von, K. C. (1835), Guide du géologue-voyageur: sur le modèle de l'agenda geognostica de $M$. Léonhard. Paris, F. G. Levrault.

Brasseur de Bourbourg, C. E. (1984), Viaje por el Istmo de Tehuantepec. Ciudad de Mexico, Fondo de Cultura Económica.

Brice, W. (2009), Myth, Legend, Reality; Edwin Laurentine Drake and the Early Oil Industry. Oil City, Oil Region Alliance.

Butt, J. (1983), James 'paraffin' Young: Founder of the Mineral Oil Industry. Edinburgh, Scotland's Cultural Heritage.

Cyphers, A; Hirth K. y Grove, D. (2008). Ideología política y sociedad en el periodo formativo: ensayos en homenaje al doctor David C. Grove. México, Universidad Nacional Autónoma de México, Instituto de Investigaciones Antropológicas.

Department of Agriculture (1869), Monthly Reports for the Year 1869. Washington, Government Printing Office.

Forbes, R.J. (1958), Studies in Early Petroleum History. Leiden, E.J. Brill.

Frederick, M. (Ed.) (1866), The Statesman's year-book. London and Cambridge, Mac Millan \& Co.

Garner, P. (2013), Leones británicos y águilas mexicanas. Negocios, política e imperio en la carrera de Weetman Pearson en México, 1889-1919. Mexico, Fondo de Cultura Económica.

Gerali, F. (2012a), «Scientific maturation and production modernization; notes on the Italian oil industry in the XIX Century», Oil Industry History, 11 (1), pp. 89-108.

Gerali, F. (2012b), «Dalle Alpi Liguri alle foci del Magra. Sperimentalismo e indagine sul territorio nel viaggio scientifico di Paolo Spadoni del 1790", Memorie dell'Accademia Lunigianese di Scienze 'Giovanni Capellini', 80, pp. 289-318.

Gerali, F. (2013), «Environment, economy, politics and technology. A brief analysis on Mexican petroleum up to early 20th century», Oil Industry History, 13 (1), pp. 237-260.

Gerali, F.; Riguzzi, P. (2013), «Los inicios de la actividad petrolera en México, 1863-1874: una nueva cronología y elementos de balance», Boletin del Archivo Histórico de Petroleros Mexicanos, 13 (2), pp. 63-87.
Glick, E. (1953), «The Tehuantepec Railroad: Mexico's White Elephant», Pacific Historical Review, 22 (4),pp. 373-382.

Glover, J.; Bevan, J. (2010), The forgotten explorers: pioneer geologists of Western Australia, 1826-1926. Perth, Hesperian Press.

Harrison, J. P. (1955), «Science and Politics: Origins and Objectives of Mid-Nineteenth Century Government Expeditions to Latin America», Hispanic American Historical Review, 35, (2), pp. 175-202.

Jiménez, M. (1840), Tratado de Farmacia Esperimental. Madrid, Imprenta de Don Narciso Sánchez.

Mazadiego Martínez, L.; Puche Riart, O. y Ortiz Menéndez, J. E. (2011) «Information about Petroleum in America prior to the Nineteenth Century». En: Ortiz Menéndez, J. E. et al. (eds.), History of Research in Mineral Resources, Madrid, Cuadernos del Museo Geominero, pp. 239-246.

Mellado, De P., (ed.) (1856), Diccionario de Artes y Manifacturas. Madrid, Paris, Establecimiento Tipográfico de Mellado.

Ministerio de Fomento (1866), Memoria presentada a S.M. el Emperador por el Ministro de Fomento Luis Robles Pezuela de los trabajos ejecutados el año de 1865. México, Imprenta de J. M. Andrade y F. Escalante.

Morelos Rodríguez, L. (2012), La geología Mexicana en el siglo $X I X$. México, Plaza y Valdés Editores.

Moro, G. (1844), Survey of the Isthmus of Tehuantepec, executed in the years 1842 and 1843, with the intent of establishing a communication between the Atlantic and Pacific oceans, and under the superintendence of a scientific commission, appointed by the projector don Jose de Garay. London, Ackermann and Co.

Murphy, J. M.; Jeffers, W. N. (1849), Nautical Routine and Stowage: With Short Rules in Navigation. New York, H. Spear.

Murphy, J. M. (1859), «The Isthmus of Tehuantepec. Its Inhabitants and Resource», Journal of the American Geographical and Statistical Society, 1 (6), pp. 162-177.

Murphy, J. M. (1860), American Ships and Ship-builders. New York, C. W. Baker.

Murphy, J. M. (1865), Petroleum in Mexico. New York, impreso del autor.

Orbegozo, de, J.; Gomez Cortina, de la, J. (1858), «Asfalto y Sal Gema». Boletín de la Sociedad Mexicana de Geografía y Estadística, v. 6, pp. 167-172.

Orozco y Berra, M., (Ed.). (1856), Apéndice al Diccionario universal de historia y geografía. Colección de artículos relativos a la República Mexicana. México, Imprenta de J. M. Andrade y F. Escalante. 
Peckham, S. (1885), Report on the production, technology, and uses of Petroleum and its products. Washington, Government Printing Office.

Pletcher, D. (1952), «A Prospecting Expedition across Central Mexico, 1856-1857», Pacific Historical Review, 21 (1), pp. 21-41.

Riguzzi, P. y F. Gerali (2015), «Los veneros del emperador. Impulso petrolero global, intereses y política del petróleo en México durante el Segundo Imperio, 1863-1867». Historia Mexicana, LXV (2), pp. 747-807.

Sánchez Graillet, L. (2009), Del chapopote al petróleo en México: historia de la construcción de una entidad 'natural' a partir de una entidad cultural, Tesis de Maestría. Universidad Nacional Autónoma de México.

Shufeldt, R. W. (1872), Reports of Explorations and Surveys: To Ascertain the Practicability of a Ship-canal Between the Atlantic and Pacific Oceans, by the Way of the Isthmus of Tehuantepec. Washington D.C., U.S. Government Printing Office.
Suárez, Arguello A. R. (2003), La batalla por Tehuantepec: el peso de los intereses privados en la relación México-Estados Unidos, 1848-1854. México, Secretaría de Relaciones Exteriores.

Torres Guerrero, M. E. (2012), Proyectos de comunicación interoceánica en el Istmo de Tehuantepec en la segunda mitad siglo XIX. Tesis de Licenciatura, Universidad Nacional Autónoma de México.

Wyse, J. P. (2007), Four centuries of geological travel: the search for knowledge on foot, bicycle, sledge and camel. London, The Geological Society.

Williams, J.J. (1852), El istmo de Tehuantepec: Resultado del reconocimiento que para la construcción de un ferro-carril de comunicación entre los océanos Atlántico y Pacifico ejecutó la comisión científica, bajo la dirección del Sr. J.G. Barnard. Ciudad de México, V. García Torres. 